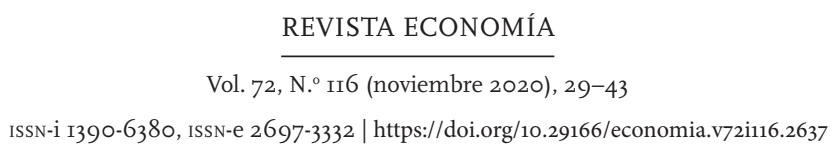

\title{
LOS CIRCUITOS ECONÓMICOS SOLIDARIOS COMO NOCIÓN REFERENCIAL
}

THE SOLIDARITY ECONOMIC CIRCUITS AS A REFERENTIAL NOTION

\author{
RAÚL GONZÁLEZ MEYER \\ Universidad Academia de Humanismo Cristiano (Chile)
}

Recepción del manuscrito: 1 de octubre de 2020

Aceptación versión final: 21 de noviembre de 2020

\begin{abstract}
RESUMEN Este artículo explora los antecedentes, componentes y sentidos, de los circuitos económicos solidarios (CES) entendidos como propuesta dentro del proyecto de construcción de una economía social y solidaria (ESs). Asimismo, comprendidos sus aspectos más característicos, busca identificar y analizar algunos desafíos para su fortalecimiento y ampliación. Para esto analiza diversos trabajos referidos tanto a la Ess como a los CEs. Como quedará claro en este trabajo, los CES no solamente se centran en el ámbito económico, sino que se sostienen en todas las dimensiones societales: sociales, culturales, ecológicas y políticas. Esto, porque están sustentados en una visión de interdependencia de esas dimensiones y en que a la economía se la entiende y promueve no autonomizada, desde principios hegemónicos propios y aislables, ligados a la combinación ontológica de escasez (como situación propia de la sociedad) y maximización (como orientación inmanente de todos los individuos)
\end{abstract}

PALABRAS CLAVE Solidaridad, territorios, economía, redes.

ABSTRACT This article explores the antecedents, contents and meaning of the Economic Solidarity Circuits (ESC) understood as a proposal within the project of construction of a Social and Solidarity Economy (SSE). Likewise, understanding its most characteristic contents, it seeks to identify and analyze some challenges for its strengthening and expansion. To do this, this work analyses various documents referring to both the social and solidarity economy, as well as the solidarity economic. As will become clear in this work, ESC not only focus on the economic sphere, but are sustained in all societal dimensions: social, cultural, ecological and political. This, because they are supported by a vision of interdependence of these dimensions and in that the economy is understood and promoted without autonomy, from its own hegemonic and isolable principles, linked to the ontological combination of scarcity and maximization.

KEYWORDS Solidarity, territories, economy, networks.

JEL CODES Z13, P32, P13, A13. 


\section{INTRODUCCIÓN}

Este artículo explora los antecedentes, contenidos y el sentido de los circuitos económicos solidarios (CES) entendidos como propuesta dentro del proyecto de construcción de una economía social y solidaria (ESs). Asimismo, comprendidos sus contenidos más característicos, busca identificar y analizar algunos desafíos para su fortalecimiento y ampliación. Como quedará claro en este trabajo, los CES no solamente se centran en el ámbito económico, sino que se sostienen en todas las dimensiones societales: sociales, culturales, ecológicas y políticas (Lopera, Mora, 2009). Esto, porque están sustentados en una visión de interdependencia de esas dimensiones y en que a la economía se la entiende y promueve no autonomizada, desde principios hegemónicos propios y aislables, ligados a la combinación ontológica de escasez y maximización.

Esta exploración se fundamenta a partir de que se ha planteado que la integración de actividades económicas solidarias en forma de circuitos se constituye en una de las posibilidades importante de fortalecimiento del sector de ess como conjunto $y$, a la vez, que ello puede ser clave para la viabilidad y ampliación de los proyectos de cada unidad económica solidaria (Silva, 2015; Vázquez y Jiménez, 2015).

\section{FUNDAMENTOS DE LA VALORIZACIÓN Y PROMOCIÓN DE LOS CES}

Si hubiese que identificar de manera precisa los factores motivantes para proponer el desarrollo de CES se podría reconocer dos, umbilicalmente conectados entre sí.

En primer lugar, como componentes de la «armazón» o «cuerpo» de la Ess, entendida esta como «otra economía», de alcance transformador y civilizatorio (Mance, 2006). Esto, como se verá, diferencia los CES de conceptos y estrategias que consideran encadenamientos y circuitos, pero dentro de enfoques de desarrollo o crecimiento convencionales, especialmente de escala regional. Los CES se ofrecen más que como una mera herramienta económica - ligada a la producción de bienes y servicios - como una modalidad que abarca o busca encarnar ideas de cambio cultural, de nuevas relaciones entre sujetos con determinados valores, de propiciar una fuerte implicación social, de creación de fuerza con capacidad de transformación social y política. Lejos están los CEs de presentarse desde una sola mayor eficiencia o eficacia económica y de comprender los intercambios como hechos impersonales y sin trazabilidad humana. Entre otros elementos, los CES reconocen e impulsan «otros mercados», como constituyentes de otras economías, basados en racionalidades alternativas a las que gestionan el capital y orientadas a expresar y construir solidaridad.

Esta orientación lleva, en la propuesta de los CES, a no reducir las posibilidades de construir mayor solidaridad solo a la acción de una economía público-estatal, pues entiende que no todo lo público debe ser estatal y no todo lo no estatal es privado con fines de lucro o movido por el interés individual (González, 2006). Es con ese telón de fondo que se valorizan los CES, así como las finanzas solidarias, la economía circular, la mutualidad, el cooperativismo campesino o de vivienda, la agroecología, por señalar algunos ejemplos. Dentro de ello, la particularidad de los ces debe ser vista en su carácter de una construcción envolvente e integradora de prácticas solidarias; como una forma de articulación de aquellas, que opera como algo más que su sola suma. 
Justamente lo último permite identificar un segundo factor detrás de la propuesta de los CES y que se refiere a un diagnóstico de debilidad de articulación de las unidades y prácticas de la Ess; es decir, las experiencias existentes no se relacionan suficientemente entre sí, como manera de fortalecerse y fortalecer el sector de la Ess (Silva, 2015). Por el contrario, por ejemplo, productores agroecológicos que se relacionan con consumidores en ferias solidarias, pueden gastar sus ingresos en empresas con características opuestas y explotadoras de los trabajadores o dañinas del medio ambiente (Le Labo, 2013). Esta «desarticulación» entre prácticas solidarias tiende a precarizarlas o no dejarlas desarrollarse; constituye una debilidad tanto individual como de la Ess, mirada como conjunto. Es esta relación entre desarticulación y debilidad, la que ha argumentado la necesidad de los CEs y el interés por sus experiencias concretas. La no existencia de estos hace que parte del valor que se crea en un territorio, y en que están presentes unidades solidarias, tienda a filtrarse desde el territorio hacia afuera o hacia componentes de la economía que reproducen otras lógicas, impidiendo la ampliación del sector solidario y también empobreciendo al territorio en que están ${ }^{1}$ (Mance, 2008).

Desde esta perspectiva de superar una debilidad de dispersión o fragmentación de la solidaridad, los CEs tienen cierta conexión con una familia de nociones que se han planteado también un fortalecimiento económico territorial solidario, como los polos territoriales de cooperación económica o la reinversión de bancas comunitarias en el territorio. El elemento común es el de las sinergias que emergen cuando esas articulaciones se producen, haciendo emerger virtudes de lo común y lo colaborativo. Se podría llamar a ello la formación de zonas solidarias y de copamiento solidario, aunque con naturales porosidades, que puede permitir, a la vez, más peso a prácticas de ese tipo en su relación con prácticas económicas que puedan tener otra racionalidad.

En los factores que se han señalado como fundamentos del interés por los CES, especialmente en el segundo de ellos, está implícita la idea que pueden ser impulsados o sostenidos. Ello significa la posibilidad de tener estrategias que pueda fortalecerlos y que hay un campo posible de instrumentos metodológicos para su fomento, entendido en buena medida como auto fomento (Silva, 2015).

\section{LA IDEA DE LOS CIRCUITOS ECONÓMICOS: CUESTIONES GENERALES}

En términos históricos, la referencia a la existencia o promoción de circuitos económicos - o propuestas similares-, no está originalmente conectada a la solidaridad; es decir, la noción de CEs es reciente con relación a la noción de circuito económico, en general.

\section{ALGUNOS ANTECEDENTES}

En su expresión tradicional, el circuito busca expresar y representar de manera simple flujos económicos, compuestos de cosas u objetos físicos (bienes), servicios y de dinero, situados y configurando, a la vez, una cierta territorialidad económica. ${ }^{2}$ En una mirada más compleja, cabe enfatizar que participan de manera imbricada con los anteriores, flujos de información que nutre a las decisiones. ${ }^{3} \mathrm{Si}$ se da un paso hacia la economía política ello debe incorporar los agentes que están gestionando y sosteniendo con su acción y trabajo esos circuitos y donde 
suele destacarse, en los textos de economía, de manera genérica y abstracta, a las familias, empresas y Estado. Pero, también, ello debe considerar grupos con grados de organización y de intereses diversos que pueden influir en las modalidades que tome el circuito.

Si se apartara relativamente de las formas más simples de representarse los circuitos, los flujos y las relaciones incluidos en ellos, debiese, a la vez, considerarse, algo que sí estará muy presente en la aproximación específica desde la concepción de los CEs: aquellos no son independientes de la cultura de cada momento y cada territorio y, por lo tanto, deben reconocer los flujos simbólicos allí presentes, sin los cuales no sería comprensible las modalidades y contenidos de dichos flujos. Es decir, junto a flujos materiales están presentes también, de manera interdependiente, flujos inmateriales que dotan de sentido a los primeros o, aún más, son un factor del desarrollo de ellos. En los contratos, por ejemplo, se actualiza todo un mundo de representaciones y no todo es puramente contractual en aquel (González, 2012, pp. 198-209). Por esto mismo, en el enfoque que se realice de los CES, se debe reconocer la importancia que desempeñan las instituciones, entendidas como campo de normas, formalizadas o no, en su papel de constitutivas de aquellos. Así, también, los procesos instituyentes que puedan darle nuevas modalidades y sentidos a dichos circuitos.

En una mirada mucho más amplia que la tradicional, ya adelantada con lo dicho anteriormente, se debe reconocer que los circuitos sobrepasan a la sola esfera mercantil, es decir, relaciones económicas no realizadas a través del mercado. Se podría decir que la sola referencia a la esfera mercantil es una representación muy insuficiente de la economía y, que, siguiendo a K. Polanyi, corresponde a la utopía liberal del mercado autorregulado que desconoce y puede buscar extinguir los otros principios de integración de los procesos económicos. Aun el propio A. Smith hablaba de la existencia y necesidad de la simpatía presente en la vida económica y otros autores han analizado la reducción de analizar la economía moderna solo desde los procesos de mercado (Mingione, 1994). Por ello, un análisis comprensivo de los circuitos debiese considerar como están presentes en ellos, junto a los aspectos propiamente mercantiles utilitarios, los de reciprocidad, redistribución y su vinculación con las economías domésticas. El rol del Estado, a la vez, asociado a cuestiones distributivas y bienestar, puede ser ampliado a roles de tipo desarrollista y de intervención sobre el ciclo económico (keynesianismo) y que pueden tener influencias en ritmos y orientaciones de diversos circuitos (Coraggio, 2009).

La consideración de estas diversas formas permite comprender de manera más compleja una territorialidad económica. Sin duda, no es fácil evaluar «la cuota» presente en la economía de cada uno de estos modos de regulación e integración (Loza, 2013). La manera dominante la representación es a través de cifras que proceden de la economía de mercado. Sin embargo, cualquiera que sea la sociedad o territorio considerado, los procesos de mercado representa solo una parte de las practicas productivas, de consumo, distributivas, de ahorro y de inversión (Mingione, 1994). Analíticamente, entonces, la perspectiva solidaria de la economía, no es que «invente» o introduzca con exclusividad las dimensiones «no mercantiles», sino que ellas están siempre presentes, aunque sea bajo la forma de subordinación a la lógica de la competencia/ganancia, de su no valorización y del desconocimiento de que eso, incluso, puede influir en la forma en que ocurre lo mercantil (González, 2012). 
CIRCUITOS TERRITORIALES: LAS ESCALAS LOCALES/REGIONALES

Dentro del campo de la geografía económica, puede introducirse en la cuestión de la espacialidad o territorialidad de las relaciones y flujos económicos. Se puede identificar que se constituyen circuitos económicos con diferentes extensiones territoriales, las que no están fijadas sino sujetas a procesos de cambios: geometrías variables, con expansiones, repliegues o redireccionamientos.

Se usan conceptos que expresan aquello. Por ejemplo, la idea de «economía mundo» lo que expresa es la existencia de una masa mínima critica de flujos y circuitos «largos», que copan y en parte constituyen al mundo y definen una territorialidad de esa escala. El capitalismo ha sido una fuerza expansiva como señalaba Marx y el mercado una base de economía (sociedad) extendida y que ha aumentado la espacialidad de las relaciones económicas, creando nuevas territorialidades, muchas veces destruyendo otras de alcance menor, como la asociada a la producción campesina y a la pequeña industria. Pero también se habla de economías nacionales, que supone que hay cierta densidad de circuitos y flujos a esa escala, que hace del concepto algo expresivo de la realidad. Se puede incluso decir que los proyectos de construir economías nacionales en países que se independizaron de formas coloniales era crear esa densidad interna de circuitos y flujos ${ }^{4}$ (González, Micheletti, 2020).

Una espacialidad que aquí interesa más por nuestro foco en los CES es la espacialidad regional/local. Ha existido una referencia a lo regional/local en la literatura sobre desarrollo desde pasada la segunda mitad del siglo pasado (González, Micheletti, 2020). Ello desde la perspectiva de unidad de representación, análisis e intervención, en la que aparecen combinados la geografía y la historia (Boudeville, 1961). Esas aproximaciones a lo regional han sido a veces reductoras, a veces más integrales y complejas; según sea, han considerado o han desconsiderado las estructuras sociales, la complejidad de los intercambios, las jerarquías y subordinaciones existentes; han sido enfoques más holísticos y dinámicos (procesuales) o más fragmentarios y estáticos; han logrado entender a lo regional/local como escalas de lo social y como resultado de una producción social o la han cosificado con características o esencialidades propias, al margen de la acción de agentes y de sus interrelaciones de cooperación o disputa (Boissier, 1990).

Pero interesa más específicamente destacar aquí que en esa trayectoria analítica, y volcada a las políticas, han surgido, con referencia a esta espacialidad, algunas nociones inspiradoras para la acción, que tienen parentesco con la de circuitos económicos o que, en cierto grado, los comprenden. Un eje de esas nociones es producir polarización económica local; es decir, producir una densificación de relaciones económicas a esa escala, que significa el aumento de las interrelaciones y flujos en su interior. ${ }^{5}$ En esa línea, se puede encontrar con nociones como polos de crecimiento (desarrollo), eslabonamientos, enlaces, medios innovadores, encadenamientos, distritos industriales, clústeres y otros. No se los analizará aquí y solo se remarcará algunos elementos que pueden ser retenidos y releídos en una propuesta de cEs. Entre ellos, está lo ya señalado de la densificación de relaciones económicas dentro de un territorio; el aumento y uso de las relaciones de proximidad; la creación de economías internas al territorio que favorecen a todos; el traspaso no mercantil de saberes e innovaciones; la integración de actividades; el evitar la filtración de excedente (valor) hacia afuera; el fortalecimiento de subsistemas productivos más integrados ${ }^{6}$ (González, Micheletti, 2020). 
A la vez, muchas de las limitaciones de esos postulados en términos de lograr los objetivos declarados que se propusieron, pueden retenerse como ejemplos de problemas que también la construcción o reforzamiento de cEs pueden presentar: la dificultad de producir integración productiva territorial; la no correspondencia entre ideas locales de desarrollo con políticas de ordenamiento territorial; la segmentación del Estado entre políticas sectoriales, y políticas territoriales; la resistencia al fortalecimiento de poderes locales (descentralización); el desconocimiento de las condiciones de las diferentes dimensiones que componen un cierto tejido económico local; desconocimiento de los procesos y agentes globales y nacionales que son fuerzas actuantes en la dinámica de los territorios (Stöhr, 1975). Entonces, aun en un plano con características de cambio limitado - con relación al de la ess- en un territorio y de aumento de sus potencialidades endógenas de desarrollo, ello no resulta simple sin tener un buen conocimiento de ese territorio (Mance, 2008): condiciones de hábitat que repercuten en la producción, actores que participan del sistema productivo del lugar, las condiciones de poder, la disponibilidad de bienes naturales — agua, tierra, vegetación, bosques, etc.- .

Esos dilemas o cuestiones adquieren un carácter especial, aunque enfrente algunos desafíos similares, cuando de lo que se trata es de fortalecer o construir CEs. Éstos tienen un carácter claramente singular respecto de otras aproximaciones, aparentemente similares. Algunos ejemplos que delinean su singularidad son: promueven las relaciones de proximidad, pero es más que la idea de circuitos cortos que se refiere especialmente al sector alimentario desde el objetivo de la disminución del número de intermediarios entre productores y consumidores (Le Labo, 2013); parten de que la cultura siempre está presente en las relaciones económicas y busca rescatar e inventar valores identitarios pero no entiende eso como la folklorización del patrimonio cultural del territorio, por ejemplo, manipulando o instrumentalizando fiestas locales (Silva, 2015); entienden al sujeto productor no solo como «recurso humano» de la actividad económica; ni al consumidor como un ente anónimo inanimado, sin responsabilidad (Lopera, Mora, 2011); dan importancia a los territorios, pero no solo como soportes o espacios de las actividades, sino como una construcción socio ambiental; se plantean la construcción de mercados democráticos y solidarios, aunque no reducen lo económico solo a lo que es monetario - como la circulación de bienes y servicios por la vía de la reciprocidad-.

\section{PROFUNDIZANDO LA CARACTERIZACIÓN Y DIMENSIONES DE LOS CES}

Como los circuitos, en general, los CES también se refieren a la circulación de flujos económicos en un movimiento incesante y circular que lleva al establecimiento de relaciones económicas de temporalidades diferentes - transitorias y regulares-. Este proceso de circulación para quienes se refieren a los cEs siempre involucra la existencia de sujetos - y no solo de categorías económicas abstractas- que participan de la producción, la distribución y el consumo, el ahorro y la inversión. Más precisamente, los CES son conjuntos integrados de unidades socio-económicas solidarias; es decir, que practican y construyen, cada una de ellas y en sus relaciones los principios de la economía solidaria. Ello busca permear a las propias relaciones mercantiles, recreando, deconstruyendo y construyendo, mercados bajo la idea de mercados solidarios ${ }^{7}$ (Razeto, 1993). 
LA SOCIABILIDAD CONVIVIAL Y LA CULTURA SOLIDARIA/COOPERATIVA

El CES, en su base molecular, busca asentarse en ciertos tipos de vinculaciones personales presentes en las empresas y unidades que le dan vida. Esto se configura de afectos y ética. Es un plano de cooperación sostenido en convivialidad, compartir, mutualidad, amistad, reciprocidad, voluntariedad. Se plantea como una idea y valor de humanización de lo económico; en que las personas y las relaciones personales «cuentan»; en que la disposición de someter y establecer supremacías personales, se experimentan como «antivalores».

En su sustrato cultural, o de construcción cultural, los CES se nutren de cultivar, —más allá de las relaciones personales directas - un medio solidario/cooperativo. Éste es un resultado y es un potenciador de esos circuitos y comprende la creación de una institucionalidad y unas normas que conscientemente buscan facilitar las relaciones de colaboración y de equidad entre las unidades económicas que componen el CEs. El predominio de una cultura y racionalidad solidaria no impide que las relaciones al interior de los circuitos sean articulaciones complejas en las que puede haber tensiones. Está el desafío de lograr plasmar principios que obliga a convenciones permanentes. Por ejemplo, en las relaciones mercantiles donde las fijaciones de precios tienen consideraciones múltiples, buscando constituir áreas de intercambios que concilie equidad, reciprocidad y responsabilidad. Así, en relaciones entre productores y consumidores surgirán referencias como comercio justo o consumo responsable. La solidaridad no es algo fijado, petrificado, sino se actualiza, crea y recrea y se va enfrentando a las circunstancias que van surgiendo.

Esta dimensión comprende cómo las prácticas solidarias valorizan los saberes y conocimientos que los pueblos y comunidades tienen y/o preservan de su herencia ancestral. Esta cultura solidaria viva, reconoce la existencia de una diversidad de saberes y conocimientos de los distintos pueblos expresadas en tradiciones de minga, trueques, medicina ancestral, ritos, comidas, uso lunar en agroecología (Silva, 2015). La educación y fomento de estas tradiciones y los saberes, en múltiples espacios constituye un alimento de la reproducción de los CES. Ello puede ir aparejado del reconocimiento de la importancia de las relaciones interculturales que se dan entre diversos pueblos y nacionalidades, aparejado de procesos de descolonización (Fernández, Sepúlveda, 2014) y que recupera o actualiza (y adapta) aspectos como la propia gastronomía, tipos de ferias y otros.

\section{ECONOMÍA Y REPRODUCCIÓN}

En cuanto a su aspecto propiamente económico, indesligable de los otros aspectos señalados, es obligatorio que los CES puedan reproducirse de manera ampliada a la manera de un proceso autopoietico (Maturana, 1997), pero que requiere decisiones y acciones, pues no es puramente espontáneo. Como dice Mance (2008), deben ser concebidos como redes de colaboración solidaria para aludir a un sistema abierto que se autorreproduce. Esto comprende esfuerzos socio organizativos de fomentar flujos de bienes y servicios, monetarios y no monetarios, en los territorios y significa, tanto que más productores se articulen a los CEs, así como ampliar el consumo de sus bienes y servicios, con sellos solidarios. Esta reproducción ampliada de los CEs supone crear lazos de retroalimentación económica entre los actores solidarios de un territorio, posibilitando producir valor económico, con un provecho para todos. 
Esos lazos son múltiples: del consumo a la producción y el trabajo; de la distribución del ingreso, a la demanda; de las finanzas a la producción; del ahorro a la inversión; de la producción a la producción; etc.

Lo anterior puede plantearse como que los CEs necesitan densificar el ecosistema territorial, entendido esto como la ampliación de las relaciones en diversas dimensiones, que permitan la construcción de sistemas económicos locales integrados, con algunos grados básicos de autocentramiento. Es ello lo que incide fuertemente en la sustentabilidad económica de los CES y en la propia constitución de estos. Esto implica mayores intradependencias territoriales, a través de flujos de provisiones, agregaciones de valor, sistemas de servicios, etc. Significa tanto una ampliación de mercados como de relaciones no mercantiles, que, además, permite y resulta de la emergencia de nuevos actores y nuevos sectores de la economía local, y en que se realizan relaciones e intercambios bajo los marcos éticos de la racionalidad económica solidaria, construyendo una nueva forma de economía (Zabala, 1997).

Esa densificación relacional necesita y significa un aumento de puestas de acuerdo entre los sujetos que producen una zona o espacio de solidaridad fortalecido. Una necesidad de «arreglos» multiplicados, entre productores, compradores, instituciones financieras populares, etc. (Mance, 2018). Por ejemplo, estimar precios justos, calidades de productos, funcionamiento de mercados, mejoramiento de equipamientos del territorio, entre los que participan del circuito. Ello significa favorecer una gobernanza colegiada lo que, a la vez, puede reforzar la eficacia económica general del circuito y el territorio.

La ampliación y proyección del CES supone la valorización y puesta en uso de los nuevos conocimientos que se generan a través de las prácticas que constituyen el circuito. Adquiere importancia el diálogo y trasmisión de saberes, innovaciones, ideas, ya no concebidas éstas como forma de apropiación de ventajas, sino como aportes a un bien común que puede mejorar al conjunto del circuito. En que aquellos conocimientos o aprendizajes dejan de operar como elementos de jerarquización y dominación, sino que asientan relaciones horizontales y participativas y de producción y apropiación más colectiva de saberes.

Lo dicho deja expreso que los CEs pueden ir cambiando su escala. Su fortalecimiento es, a la vez, «hacia dentro» $y$ «hacia fuera». Por un lado, es de densificación al integrar actividades adicionales antes resueltas por unidades con lógicas «no solidarias» — capitalistas, anti-asociativas, por ejemplo- y por otro lado es de extensividad abarcando una geografía económica mayor. En este sentido, aunque con una fuerte valorización territorial, los CES no son concebidos de manera autárquica y cerrada y aun los circuitos económicos y solidarios cortos pueden ampliar los ecosistemas territoriales de implantación y funcionamiento. ${ }^{8}$ Ello puede significar desarrollar experiencias en territorios mayores e integrar nuevos actores en el proceso. ${ }^{9}$

\section{EXCEDENTES Y AUTONOMÍA}

Un punto crucial de la reproducción y ampliación de esta zona solidaria que constituye los CES, está asociado a las capacidades que este tiene de usar los excedentes que sus diversas unidades económicas producen en la expansión del circuito. Aquí se da una relación de interdependencia positiva entre cuán fuerte es el ces y cuánto excedente puede estar disponible para su ampliación económica - que se sabe es, a la vez, ampliación de modos relacionales, culturales y 
políticos-: mientras más denso y amplio es un CES más posibilidades tendrá de generar un excedente y mientras mayor sea el excedente que genera más posibilidades tendrá de ampliar esa «zona solidaria» expresada en el CEs.

También, esto puede ser expresado como que mientras más integral o integrado es un CES - es decir, operado por agentes del sector de la economía solidaria- mayores opciones de apropiación del excedente económico podrá haber en beneficio del fortalecimiento y ampliación del circuito. Un ejemplo concreto y clave en esto es la existencia o no existencia en un CES de agentes que tengan esa misma racionalidad en el terreno de las finanzas, bajo denominaciones de bancos populares, banca ética, bancos comunitarios, finanzas solidarias, cooperativas de ahorro y crédito, etc. Con ello, se fortalece que el financiamiento juegue roles activos en términos del desarrollo social, territorial y ambiental, bajo el prisma de la solidaridad y cooperación. Dicho en negativo, cuanto más integral es el CES, se reduce la dependencia de estos, disminuyendo la posibilidad que el valor creado dentro de las unidades solidarias se «filtre»o sea capturado o expropiado, desde agentes con otras lógicas económicas, en particular lógicas centradas en la acumulación de capital sin compromiso con orientaciones solidarias en y con los territorios. Ello limita las características más solidarias que pueden ir tomando los mercados cuando integran producción, consumo, finanzas y comercialización, al trasladar valor agregado a agentes que construyen un mercado marcado por la competencia extrema, la dinámica de concentración y la asimetría de poderes.

Esa integralidad e integración de los CES y su manejo de un excedente económico mayor, aumenta su capacidad de favorecer emprendimientos que son claves para enfrentar desafíos de una lógica de economía solidaria integrada. Un ejemplo es el de la producción de energía y la orientación del uso de fuentes renovables en sectores que, a la vez, son propicios para potenciar dicho tipo de economía, como el de la agroecología y el abastecimiento de alimentos. Así, el reforzamiento mutuo de circuitos alimenticios cortos y producción local de energías han sido y pueden ser la base de comienzos de CES o de su reforzamiento, a partir de circuitos de carácter parcial. Igualmente, al favorecer emprendimientos solidarios que hagan más integral un circuito, el excedente económico puede ser usado en reforzar una cultura y en crear capacidades logísticas para que aumente el consumo local de alimentos, para preservar ciertas tradiciones, para informar las condiciones de producción, los compromisos éticos y sociales de los productores, la calidad de los productos, la forma en que se fijan los precios o la calidad de ciertos servicios.

\section{PARTICIPACIÓN, PODER Y PROTAGONISMO}

Resta agregar en este subrayar las propiedades concebidas para los CES, la forma de relacionar la economía con la democracia y la participación. Aquéllos se arraigan y buscan construir y orientar espacios económicos (y sociales) comunitarios, sustentados en grados altos de participación (Lopera, 2008). Poseen como característica sustantiva, y no solamente instrumental, una aproximación participativa que busca ampliarse en el tiempo, entendido como algo en permanente construcción y evaluación. Su primera expresión está en la base de las actividades económicas donde priman los valores de la autonomía, la autogestión y el empoderamiento de las personas; pero, también, en niveles más agregados de la actoría de construcción y gestión de los CEs. 
En este nivel y escala más agregados, es importante la capacidad política de construcción social de instituciones, procedimientos, normas, que sustenten, resguarden y transformen los principios solidarios y cooperativos de los CES. Ésta permite señalar que los CES no se fundan solamente en una actualización de prácticas, valores y lógicas solidarias que puedan estar ya presentes en la sociedad - y que de hecho explican parte de sus expresiones- sino, también, y muy fundamentalmente, en la construcción de condiciones institucionales y «de entorno» para su surgimiento, mayor densidad y proyección.

Esta última afirmación permite señalar algo que complementa lo aseverado respecto del uso de los excedentes en un CEs. Las racionalidades económicas presentes en un territorio son variadas y los CEs tienen vínculos complejos con ese entramado social, cultural y político del territorio. Se desarrollan y existen en escenarios de interdependencia con agentes y lógicas que no expresan — por intereses, por ideología, por incredulidad- esas mismas racionalidades solidario-cooperativas. Esos agentes pueden ser diversos, entre ellos grandes empresas con fuerte lógica acumulativa o Estados - centrales y locales - con una ideología del progreso asociada solo al crecimiento de bienes. Como se señaló antes, el fortalecimiento y la expansión de los CEs tiene que ver con su capacidad de integrar actividades a la órbita de su racionalidad solidaria; pero también con sus capacidades de establecer relaciones con esos otros agentes que impidan su cooptación y, en algunos casos, que permitan irradiar los valores y principios de los CEs, hacia esos otros agentes/lógicas.

Es allí donde se hace importante, como parte del fortalecimiento de los CEs, el establecer relaciones con lo que se pudiese definir como fuerzas auxiliares, efectivas o potenciales, representadas por entidades de diferente tipo y origen que son cercanas o comprometidas con orientaciones económicas solidarias en la sociedad y los territorios. En ello pueden estar presentes colectividades públicas locales, algunos sectores del Estado, áreas de universidades, organizaciones no gubernamentales, asociaciones profesionales y diversas agrupaciones sociales de base. Todas éstas pueden cumplir roles claves en términos de soportes diversos para los CES por su interés en avanzar hacia una economía más solidaria. ${ }^{10}$

Esas prácticas de articulación pueden ser la base, además, de ganar capacidades de incidencia en la política, que genere formas de gobernanza más democrática y plural, que abra mejores caminos para el desarrollo de los CEs. ${ }^{11}$ Esto último, no debe ser entendido como un rol o actividad circunstancial de los CES, sino que expresa la dimensión de «sujeto político» o «sujeto de cambio social» conque también han sido concebidos. Esto significa afirmar que su autoexpansión no radica solo en procesos económicos que van ampliando los límites o fronteras de zonas solidarias más densas, sino también en la capacidad política capaz de gestar conciencia y estrategias de cambio social e intervenir en las orientaciones de los territorios en los cuales existen, incluyendo la producción de la política pública.

Eso obliga a reconocer la dimensión política de su propio desarrollo y del lugar de ello en los territorios; la importancia de su incidencia política para fortalecer instituciones, normas y políticas, locales, que promuevan la economía solidaria en los territorios; así como lo clave de la articulación con movimientos sociales - ecologistas, feministas, jóvenes, sindicatos - para la promoción de ces y asegurar, así, formas adecuadas a sus principios, con relación a la gestión de bienes y políticas como sobre la tierra, el agua, la tecnología y crédito, particularmente 
frente a la disputa de los mismos, por la presencia de los agronegocios, los encadenamientos productivos en función de la competencia mundial, el extractivismo y otras formas que tiene la economía dominante para instalarse y usar los territorios.

Esta actoría e incidencia por el cambio puede también platearse como la transformación de las modalidades y direccionamientos de los flujos existentes en un territorio. Como dice Mance, un territorio siempre es cruzado por flujos diversos: económicos, naturales, culturales. Partiendo de ello un proceso de cambio en el sentido que se ha señalado aquí significa reorganizarlos solidariamente para constituir circuitos económicos solidarios (Mance, 2011). Es decir, siempre hay flujos y la pregunta es por las características de ellos y como pueden ir tomando la forma dominante de circuitos solidarios. ${ }^{12}$

\section{AMBIENTE Y NATURALEZA}

Restaría señalar que los CES se plantean reestablecer y construir una relación armonizada entre economía, territorio y naturaleza. En algunos casos, para defender prácticas de ese tipo que han logrado sostenerse en el tiempo, en otros se presenta como una vía de reconciliar territorio, medio ambiente y economía. Desde los ces está la potencialidad de asumir el territorio de vida, trabajo y reproducción, como algo que esta metabólicamente unido a la naturaleza. Significa una mayor conciencia de esa relación, lo que comprende la capacidad de lectura ecológica sobre la interdependencia entre todo y entre todos, y de los impactos ambientales de los intercambios económicos. ${ }^{13}$ Es lo que Anguieta (2013) denomina la biocultura, en donde la diversidad biológica y la cultura son mutuamente dependientes y geográficamente coexistentes.

En ese sentido, los CEs leen los procesos de producción, distribución, consumo, desarrollo, dentro de una envoltura ambiental y las relaciones ontológicas (Escobar, 1999) que tienen las comunidades y personas con la naturaleza. Ello obliga, por fidelidad con los principios de los CES, a la consideración de aspectos como el origen de los recursos, los medios de transporte usados, los sistemas energéticos y su aprovisionamiento, las formas de distribución, la gestión de los «desechos», las formas de alimentación, los tipos de valor agregado a los bienes, la consideración de la salud, las estructuras de consumo o el tipo de agricultura. Nada debiese quedar excluido de ser observado desde el obligado metabolismo humanidad y naturaleza.

\section{ALGUNAS CONSIDERACIONES FINALES}

De todo lo dicho, se puede sintetizar que un CES es una modalidad económica que valoriza las relaciones humanas en que no se enfrenta a los otros como instrumentos de los fines propios; que construye y fortalece los lazos sociales marcados por la solidaridad, la cooperación, la participación, la transparencia y la equidad de los intercambios; que entiende ello como una cultura que concilia lo económico con valores como los anteriores; que supone también como parte de su desarrollo una capacidad política de incidir en la realidad (Le Labo, 2013, p. 9). De ello se puede desprender que un proceso de desarrollo - ampliación y densificaciónde los CEs supone una acumulación de «capitales» de varios tipos o en varias dimensiones absolutamente imbricadas: capital económico, capital cultural; capital social y capital político. 
A la vez, la concepción y la práctica de los ces deben entenderse jugando posiciones multiescalares. A una escala «micro local» promueven y se sustentan en tipos de relaciones de proximidad que hacen primar la solidaridad cara a cara, la convivencialidad, el respeto; asimismo, la conciencia y la responsabilidad respecto de sus acciones y los impactos de sus actividades e intercambios económicos. A una escala «micro local» se asume la perspectiva del desarrollo de un territorio a partir de la conciencia de compartirlo, en que hay un campo posible para iniciativas que se pueden articular y constituir un proceso integrado movimiento. A una escala «meso» o intermedia pueden desarrollarse más ampliamente articulaciones con mayor nivel de agregación y configurar ecosistemas virtuosos de tipo solidario cooperativo y sostenible e integrando mayor cantidad de «fuerzas auxiliares» dentro de la orbitas de los CEs (Fernández, 2013). A una escala más «macro», las experiencias y los atributos señalados en las escalas anteriores pueden lograr bosquejar una alternativa posible frente a las formas dominantes actuales alcanzando, incluso, que puedan llegar a determinarse instituciones y normas nacionales favorables para el desarrollo de CEs, en campos del conocimiento, del financiamiento, de alianzas, de planes, etc.

Esto puede y debe alcanzar también escalas más globales en tanto la idea y promoción de la Ess, la construcción de otra economía, tiene alcances globales, aunque no bajo formas imperialistas o de dependencia. Así, la integración e intercambio de conocimientos, experiencias, no tienen fronteras nacionales y, aún más, aquellas son un recurso importante para el desarrollo de los CEs. Aunque estos se asientan en una idea de una construcción «desde abajo» de otro sistema económico, suponen, a la vez, construir espacios y conexiones amplias «hacia los lados» y no solo «hacia arriba», construyendo un global más horizontal que jerárquico. El aumento de esas redes internacionales solidarias puede tener efectos virtuosos para el fortalecimiento del desarrollo endógeno de los territorios con base en estos circuitos y redes solidarias.

Todo lo señalado sobre las potencialidades de los CEs, aunque intercalado de problemáticas y desafíos, se ha movido en el campo de una noción referencial que rescatando y leyendo procesos existentes los proyecta hacia delante como posibilidad. Sin embargo, esto debe ser combinado con análisis concretos y dinámicos (diacrónicos) de realidades en que estos circuitos estén en algún grado presentes. Ello permitirá ver las distancias, brechas, dificultades, con relación a esas nociones referenciales. Y, a la vez, revisar estas, integrando o combinando nuevos elementos. Un estudio, al respecto, muestra las diferencias entre circuitos en variados aspectos: las situaciones de autonomía y sustentabilidad o de dependencia de mercados convencionales; la capacidad de negociación; la extensión y distancia de los mercados para sus productos; la presencia de flujos no monetarios; el carácter más compacto e integrado o más poroso y parcial; la alianzas con otros actores; la posibilidades de gestión y control de un circuito; el desarrollo y papel de la comunicación; las formas de liderazgo (Silva, 2015).

Aspectos tan significativos como los señalados, entre los más importantes; definen realidades, procesos y desafíos diferentes de los CEs. Esto permite desprender que su potenciación debe combinar y hacer dialogar las ideas referenciales que apelan a sus sentidos más profundos, con las condiciones históricas y situacionales específicas que presentan. Solo lo primero, puede construir una entelequia o un «tipo ideal» distanciado de la realidad; solo lo segundo, puede hacer perder su potencial transformador y aportador a nuevas formas y contenidos de la economía. 


\section{NOTAS}

1 Es interesante para fortalecer la importancia de este punto que algunos estudios han evaluado positivamente el mayor impacto en el bienestar y prosperidad sociales de localidades donde las empresas tienen arraigo y relaciones locales respecto de otras en que predominan estructuras empresariales externas sin pertenencia. Estudios citados en Le Labo de l'economie sociale et solidaire (2013) realizados en universidades norteamericanas (ver referencias).

2 El primero en pensar la economía de una sociedad - más bien la producción - en términos de circuito económico fue François Quesnay a mediados del siglo XviıI que hizo parte de la corriente fisiocrática. Formado en la ciencia médica llevó la idea del cuerpo humano a la forma de existir de la economía como interacciones constituidas de manera asimilable a la existencia de polos y flujos.

3 Estos flujos de información pueden ser bajo forma mercantil - se venden y compran - como no mercantiles que fluyen a través de las relaciones económicas y sociales, de conversaciones, y se transmiten dentro de los espacios socio-económicos representando una externalidad positiva para las unidades económicas, aunque pueden ser apropiadas de manera asimétrica.

4 Justamente, se criticaba que el colonialismo había generado economías extravertidas — con circuitos hacia afuera y no hacia dentro de la nación- o economías «enclave» en que los sectores exportadores no generaban circuitos con el resto de la economía. La noción de heterogeneidad estructural, ampliamente usada por Aníbal Pinto y en enfoques cepalianos podría entenderse, desde ese punto de vista, como la obturación de la posibilidad de densificar flujos por las grandes distancias tecnológicas entre agentes y sectores de la economía (González, 2013).

5 En términos declarativos, en América Latina esas políticas buscan disminuir los desequilibrios regionales, integrar zonas atrasadas, y disminuir las concentraciones muy altas en las capitales metropolitanas (De Mattos, 2003).

6 Algunos de esos conceptos y análisis históricos asociados lograron ir más allá de solo consideraciones económico-tecnológicas como los distritos industriales que relevaron la importancia de la identidad y la cultura en los procesos regionales y, en general, valorizaron la política, normalmente desde una perspectiva - centralista - en tanto varios de ellos buscaron hacer en cierto grado frente a «desequilibrios» o desigualdades interregionales producidos por el capitalismo y el mercado (Becattini, 1989)

7 Me refiero a una cooperación subjetivada como tal por los sujetos, y no solo a la cooperación social propia de una economía y sociedad con división del trabajo característica de las economías modernas. En éstas, la cooperación social es clave - lo que Marx entendió por la socialización de las fuerzas productivas - pero puede ser una cooperación «des-subjetivada» como tal; es una interdependencia que se vive como lejanía al mismo tiempo. En el caso de los CES, éstos serían reforzadores de un lazo social subjetivadamente cooperativo en ámbitos locales.

8 Como lo plantea Razeto (1994), la articulación se va logrando entre diversas organizaciones, de naturaleza diferente, en estructuras superiores, complejas que van alcanzando niveles de autonomía según su grado de maduración, y pasan de las cadenas productivas a integrar procesos de financiamiento, producción, comercialización y consumo para ganar mayor autonomía frente a las organizaciones capitalistas.

9 Esas mayores escalas naturalmente tienen desafíos o riesgos, pero necesarios de asumir. Por ejemplo, que se haga menos fuerte la cooperación y la dimensión relacional; o el aumento de tomas de decisión sin participación y concertación efectiva. La ampliación de la escala de los ces puede darse de varias formas: crecimiento del tamaño de la estructura — diversificación de actividades, por ejemplo-; cooperación con otros CES; reproducción de una experiencia por otros actores; entrada en un tejido o red; transformación de la lógica de estructuras convencionales; influencia comunicacional o política que influye en los decidores de política y el impulso de cEs (Le Labo, 2013).

10 Así se señalan por ejemplo: (a) soporte de capacitación técnica, referidos a procesos de capacitación expresados en escuelas de formación, talleres y cursos, que se realizan al interior de los cEs bajo formas de educación popular e interaprendizaje; y (b) soporte comunicacional para comunicar, concientizar y 
sensibilizar al interior y fuera de los CES sobre la economía solidaria bajo formas como redes sociales, periódico, radios comunitarias, radios alto parlantes y otros mecanismos de comunicación e información (Silva, 2015).

11 Un ejemplo avanzado de fuerza auxiliar puede ser un observatorio para el desarrollo de cEs que capitalice las experiencias y resalte los impactos positivos, los tipos de gobernanza existentes, la condición económica histórica, etc. (Le Labo, 2013).

12 Por ello, señala el propio Mance, sin investigar los flujos económicos de un territorio no hay cómo proyectar adecuadamente los circuitos económicos solidarios y tampoco promover adecuadamente su desarrollo sostenible. De ahí la importancia de un mapeo de flujos y diagnósticos económicos (Mance, 2011). 13 Como dice con precisión y sensibilida A. Escobar: «La flor no existe, sino que inter-existe». Inspirado en Thich Nhat Hanh que sostiene que cualquier cosa o persona tiene una relación de interSer con todo lo demás. Ni una simple flor puede existir aislada de sí misma, solo puede inter-ser con la totalidad del cosmos. Y lo mismo ocurre también con nosotros.

\section{REFERENCIAS}

Argueta, A. (2020). Patrimonio biocultural y regiones de esperanza. Diálogos ambientales. (s. d.).

Becattini G. (1989). Riflessioni sul distretto industriale marshalliano come concetto socio-economico. Stato e Mercato, 25, 111-128.

Boisier S (1990). Los tiempos verbales del desarrollo regional en América Latina. Ilpes.

Boudeville J. (1961). Les espaces économiques. Presses universitaires de France.

Coraggio, J. L. (2009). Polanyi y la economía social y solidaria en América Latina. En ¿Qué es lo económico? Ciccus.

De Mattos C. (2003). Paradigmas, modelos y estrategias en la práctica latinoamericana de planificación regional. Ilpes.

Escobar, A. (2014). Sentipensar con la tierra: nuevas lecturas sobre desarrollo, territorio y diferencia. (Colección Pensamiento Vivo). Universidad Autónoma Latinoamericana.

Fernández, B. y Sepúlveda, B. (2014). Pueblos indígenas, saberes y descolonización: procesos interculturales en América Latina. Revista Polis, 13(38), (s. d.).

González-Meyer, R., Micheletti, S., Adasme-Jara, B. (2020). El surgimiento de la escala regional y local en el debate sobre desarrollo: reconstitución histórica y balance teórico. Iberoamerican Journal of Development Studies. http://10.26754/ojs_ried/ijds.496

González, R. (2016). La perspectiva y el debate acerca de una economía cooperativa, solidaria y autogestionaria, como centro de una economía social. Revista de la Academia, 21, pp. 5-26.

González, R. (2013). Revisitando la historia de las teorías del desarrollo. Revista Cuhso, 23(1), 55-91.

González, R. (2012). De la economía a la socioeconomía. En R. Gonzalez y H. Richards (eds.), Hacia otras economías: critica al paradigma dominante. LOM.

Le Labo de l'economie sociale et solidaire. (2013). Les circuits courts de l'Économie Sociale et Solidaire: une approche économique qui a fait ses preuves (tome II).

Lopera, L. y Mora, B. (julio-diciembre, 2009). Los circuitos económicos solidarios: espacio de relaciones y consensos. Semestre Económico, 12(25), pp. 81-93.

Lopera, L. y Mora, B. (2011). Los caminos del desarrollo: los circuitos económicos solidarios como posibilidad de inclusión económica y social de la sociedad civil. Ix Congreso Anual de Investigación sobre el Tercer Sector. México. http://www.lasociedadcivil.org/docs/ciberteca/.

Mance, E. (2011). Circuitos económicos solidarios. (Sumario de la exposición). (s.d.). 
Mance, E. (2008). La revolución de las redes. La colaboración solidaria como una alternativa pos capitalista a la globalización actual. Universidad Autónoma de México.

Mance, E. (2006). Redes de colaboración solidaria. Aspectos económico filosóficos: complejidad y liberación. Otras voces, Universidad Autónoma de la ciudad de México.

Maturana, H. (1997). De máquinas y seres vivos, autopoiesis de la organización de lo vivo. Editorial Universitaria.

Mingione, E. (1994). Las sociedades fragmentadas (Una sociología de la vida económica. Mas allá del paradigma del mercado). Ministerio del Trabajo y Seguridad Social.

Razeto, L. (1993). Los caminos de la economía de solidaridad. Vivarium.

Silva, G. (2015). Circuitos económicos solidarios y puesta en valor del patrimonio. En Economía Solidaria Patrimonio Cultural de los Pueblos. Universidad Politécnica Salesiana. (s. d.).

Stöhr, W. (1975). El desarrollo regional en América Latina: experiencias y perspectivas. SIAP.

Vázquez, L. y Jiménez, J. (2015). Introducción. En Economía solidaria patrimonio cultural de los pueblos. (s. d.).

Zabala, H. (1997). Integración y formación de circuitos económicos. cInCOA. http://www.messe.ec 